\title{
Ultrasound-Guided percutaneous neuromodulation in non-radiating low back pain
}

\author{
Sanmartin Enriquez F. 1,2,3 Valera Garrido F. ${ }^{1,2,3}$ Álvarez Prats D. 1,2,3 Carvajal Fernández O. ${ }^{1,2,3}$ \\ ${ }^{1}$ Centro de Fisioterapia FyS, Narón, A Coruña, Spain \\ ${ }^{2}$ MVClinic, Madrid, Spain \\ ${ }^{3}$ Fisioterapia Océano, Madrid, Spain
}

Rev Fisioter Invasiva 2019;2:124.

\begin{abstract}
Keywords

- lumbar pain

- ultrasound-guided percutaneous neuromodulation

- low frequency

Background Low back pain is very common, affecting 15-20\% of the population each year, and representing of the main causes of physical therapy consultations. Multiple treatments have been defined for chronic low back pain, however, the findings are still controversial, and therefore new and improved solutions are necessary for the population who suffers from low back pain.

Aims To evaluate the effectiveness of ultrasound-guided percutaneous neuromodulation (US-guided PNM) in patients with non-radiating low back pain.

Material and Methods An experimental study was performed in patients with nonradiating low back pain, between the months of march and may of 2018 at the F\&SNarón Physical Therapy clinic, in A Coruña. Functionality was evaluated via the Oswestry questionnaire and pain was evaluated using the visual analog scale (VAS). US-guided NMP was applied to stimulate the medial branch of a L2 posterior ramus and the iliohypogastric and ilioinguinal nerves, following the protocol described by Valera \& Minaya, which consists of the application of a PES type current at $10 \mathrm{~Hz}$ and 240 microseconds, during 15 seconds and for 6 applications. In total, 3 sessions were applied (sequence 1:7:7), once a week after the first week of initiating treatment. Results Initially, 12 patients participated in the study, aged between 32 and 59 years. The mean age was 41.4 years. Two of the patients abandoned the study due to personal reasons, unrelated to the research. The final sample consisted of 10 subjects, $50 \%$ of each sex. $80 \%$ of patients improved after the application of the treatment protocol. An important decrease in activity limitations was observed, from 14 to 4.35 points out of 100 according to the Oswestry questionnaire, and a decrease of 6.8 to 2.15 points out of 10 was observed on the VAS scale, which was statistically significant according to the Wilcoxon test $(p<0,05)$.

Conclusions The ultrasound-guided percutaneous neuromodulation technique used was effective, obtaining positive results in relation to pain and functionality. Clinical studies are necessary with a greater sample size to confirm these findings.
\end{abstract}

DOI https://doi.org/ $10.1055 / \mathrm{s}-0039-3402503$. ISSN 2386-4591.
Copyright $\odot 2019$ by Thieme Revinter Publicações Ltda, Rio de Janeiro, Brazil
License terms 